\title{
Chronic Cancer Pain
}

National Cancer Institute

\section{Source}

National Cancer Institute. Chronic Cancer Pain. NCI Thesaurus. Code C9467.

Chronic pain that results from cancer and/or its treatment. The mechanism for chronic cancer pain may be inflammatory, neuropathic, ischemic, and/or mechanical in nature. 